\title{
Patriagonia, de Ivonne Coñuecar. Revuelta geopoética de cuerpo/territorio ${ }^{1}$
}

\author{
Patriagonia, by Ivonne Coñuecar. \\ Geopoetic Revolt of Body/Territory \\ Kemy Oyarzún Vaccaro \\ Universidad de Chile \\ koyarzun@gmail.com
}
"la historia la hacen los pueblos / la memoria es una bomba de tiempo que debemos desactivar" (Coñuecar 84).

"quien habla de heridas revive al violador que con piedras callamos porque no queríamos" (135).

\section{Resumen}

Esta lectura de Patriagonia (2014), poemario escrito por la poeta Huichille-chilena, Ivonne Coñuecar, intenta dar cuenta de la estética de tres de sus textos reunidos en esta edición: Catabática (2011), Adiabática (2009) y Anabática (inédito hasta 2014) desde una mirada feminista y queer, interseccional y descolonial. La lectura explora la urdimbre de relaciones identitarias no binarias, de territorio y estado-nación, como una serie de revueltas geodésicas y eróticas, geopoéticas y políticas. La hablante poética da cuenta de chispazos y desplazamientos de memoria rupturista a partir de múltiples agenciamientos de poder que abarcan el cuerpo, la familia heteropatriarcal y la centralidad capital del Estado neoliberal.

Palabras clave: Feminismo, interseccionalidad, poesía, identidades, territorios.

\section{Abstract}

This reading of Patriagonia (2014), a collection of poems written by the Huichille-Chilean poet, Ivonne Coñuecar, delves into the aesthetics of three of her texts gathered in this edition: Catabática (2011), Adiabática (2009) and Anabática (unpublished until 2014) from a feminist and queer, intersectional and decolonial perspective. We explore the weavings of non-binary relationships of identity, territory and nation-state, as a series of geodesic and erotic, geopoetic and political revolts. The poetic speaker accounts for sparks and disruptive memory shifts, amidst multiple assemblages of power that encompass the body, the heteropatriarchal family and the capital centrality of the neoliberal state.

Keywords: Feminism, intersectionality, poetry, identities, territories.

1 Agradecemos a Fondecyt, pues este artículo es producto del Proyecto ANID-Fondecyt 1140731 "Imaginarios del cuerpo en Literatura Chilena Contemporánea: 1970-2010". 


\section{Introducción}

Empiezo a escribir este texto a un día del aniversario de la Revuelta del 18 de octubre de 2019. Termino tres días después de las elecciones para una nueva Constitución. Lo leo desde feminismos interseccionales, comunitarios, en los que sexo, género, clase y pueblo-nación se problematizan, articulan y desmantelan. Me adentro en el poemario y emerge la nación-estado en la figura del rizoma, aquí, donde se ha pulverizado el sentido de lo patrio a partir de una serie de estallidos que desatan conexiones heterogéneas de eslabones políticos, poéticos, imaginarios, sociales, subjetivos, "hasta que la dignidad se haga costumbre", como dice la consigna de la Revuelta (O19). Este no es un libro, me digo al abrir Patriagonia ${ }^{2}$ está instalado performáticamente en la figura de la circulación en línea a partir de un regalo que me ha hecho Fernanda Moraga por el correo electrónico. ${ }^{3}$ Es curiosamente un homenaje a la Revuelta esta conexión en serie - un acoplamiento físico, eléctrico, de yo y no-yo, flujos en estado libre-. Vuelve a mí la multiplicación de géneros, sexos, pueblas y pueblos, identidades celebratorias. Vuelvo a escuchar los gritos afuera de mi oficina en Vicuña Mackenna. El ruido de balines. El “Chile despertó". Los 400 ojos cegados, "para que nunca más dejemos de ver", —decía el grafiti-. Me conecto y ese don patriagónico invade mi cotidianidad de otra manera, sentada como estoy hora tras hora ante la ramificación de sentidos y labores del Zoom. No es ni árbol ni raíz este texto. No tiene hojas. Tampoco es dicotómico porque su discontinuidad lo impide. Se desliza, a veces desgarrado, a veces catatónico, furiosa y celebratoriamente agónico. Así, Patriagonia se realiza como relectura en serie, actualizable. Es una reactualización capaz de establecer conexiones inestables entre la memoria de ese evento O19 y este hoy, aquí, en el confinamiento del covid-19.

El poemario de Ivonne Coñuecar invoca una serie de intensidades sublevadas en las figuras de un cuerpo desmembrado llamado nación, un excedente innombrado de parias, una multiplicación inagotable de naciones descentradas y en merma, pero no por ello menos plurales. Mejor aún: se trata de un cuerpo textual desmembrable en la producción misma del poemario. No es consumible este proceso, me digo. Se trata más bien de mapas deseantes en expansión que se desperdigan y desplazan en engarces, órganos a medio armar, flujos bio y geopoéticos. Pero también risotada, insolencias sin metáforas, con acumulación de oprobios, sujeciones y rebeldías. Sin duda, presencio la anexión de poesía y los múltiples registros colectivos de enunciación que operan en mí para desarticular los nombres patrios, los nombres propios e impropios, para desmontar y pulverizar los agenciamientos entre los signos, "sus" objetos y dominaciones; los regímenes subjetivos y las sublevaciones que desata.

2 Selecciono Patriagonia, una colección poética de Ivonne Coñuecar publicada por Ediciones Lom, en 2014, para esta reflexión sobre crisis y literatura chilena de comienzos del siglo xxı. El texto reúne una trilogía: Catabática (2011), Adiabática (2009) y Anabática (inédito hasta 2014). En adelante, toda la paginación de los poemas en paréntesis refiere a Patriagonia.

3 Fernanda ha escrito un texto que también leo y con el que coincido respecto al sujeto fronterizo. Ver Referencias. 
Hablamos de crisis de la nación-estado, me digo y recuerdo las palabras de Gabriela Mistral: "Cuando escribimos en la América con pretensiones de universalidad, suele parecerme un vagabundaje sin sentido (Mistral en Subercaseaux 15), “vagabundear / dejando velas en cementerios", dirá Coñuecar (16). Aunque Patriagonia reniega de Mistral en algún punto (de la matria, digo, no del vagabundaje sin sentido), le sobrepongo la patria del mismo texto mistraliano: "Era hermosa de verla antes de que pasase a la quemazón insensata de frontera y a la rapiñería suelta" (Mistral en Subercaseaux 16). Patriagonia transita efectivamente hacia una geodésica de deshielos en la que la sexualidad deseante coincide con una gran quemazón que instala las fronteras y transforma el vagabundaje en "rapiñería suelta". "Chile no tiene oportunidades cuando presento mi demanda de cariños y derechos... escucharte gemir mientras las calles me cierran sus puertas / y yo travesti digo democracia bajo los neones" (71), punza la oralidad del texto.

A 50 años de la Unidad Popular, el paso por la dictadura dejó atrás la defensa de soberanía popular propia de los imaginarios latinoamericanos de la liberación. En el contexto de los Documentos de Santa Fe (1980-1985), la idea de nación se contrapone hoy a las luchas plurinacionales y a los imaginarios antimperialistas de las "naciones emergentes". Santa Fe reafirmó la noción del "enemigo interno", las guerras de fronteras, el trato del Estado represivo contra el Wallmapu y contra las protestas de 2006, 2011, 2014, 2018, y particularmente contra la Revuelta de octubre 2019.

\section{Herida libertaria: Cartografías fisuradas}

Me intriga el ícono del paraje patrio como punto de partida; notoria fluidez en la trama discursiva de la nación-estado. Entonces, el poemario asalta como bitácora que incita a perderse en los procesos de su realización, a partir de un cuerpo patrio que "ya no es", que nunca fue uno. Distópica, Patriagonia empieza por desmitificar esos injertos imaginarios de país, esas junturas de sometimiento con sus inxilios y exilios. Crisis de literatura y crisis de nación se articulan en ese "ya no", con el que comienza el texto:

recordé entonces que ya no

que la muerte se lo había llevado que mi Patagonia

que mi tierra que mi niñez

esta fisura por donde el viento silba / serena el latido

4 Los documentos de Santa Fe son documentos de la cia redactados en la ciudad de Santa Fe entre los años 1980 y 1986. Fueron inspirados frente al temor de la propagación izquierdista en la región y han servido a los procesos de neocolonización y a la "pacificación" de los territorios indígenas, todo lo cual recrudeció como base operativa del fortalecimiento de la política de dominación estadounidense en América Latina a partir de esos años. Entre sus puntos más importantes están: instalación de gobiernos próximos a los EE. UU. con poca capacidad de gestión y dependientes de asesores enviados por estos; promover reformas neoliberales que facilitasen la inversión estadounidense y europea en los países latinoamericanos, además de debilitar a las economías y a las empresas locales. 
abisal / deste / mi estropajo corazón

desta / espera sin sentido / deste

volver pensando que era antes (9)

Dijeron que mejor no volviera (13).

Pero la hablante vuelve. Una y otra vez. Desde el hielo y las cenizas. ¿No es Chile mismo esa cartografía "fisurada" (9), esa "alma llena de islas" (20) capaz de renegar de su fragmentación en la propia metáfora patria de la unidad nacional? ¿No es acaso un "caos en el silencio desolado de la Patagonia" (20), esta "fractura continental" (20) que llamamos patria, "cicatriz colonial" (20), muerte secuencial que corroe hasta "las fronteras de la piel" (26) sobre todo a partir del pater familias y la matria fálica heteronormativa? En Patriagonia, y muchas de las críticas de las feministas de Abya Yala, la imagen de la rapiña patriarcal expone el cuerpo de las mujeres al extractivismo, violación capitalista de la naturaleza a través de la apropiación ilimitada de nuestros recursos: mercantilización de las aguas, la tierra, los bosques, la flora y la fauna de los territorios. ${ }^{5}$ Más bien - y cito el poemario - se trataría de una "herida libertaria" abierta por memorias filogenéticas de violaciones patriarcales, edípicas, lesbofóbicas, de contornos materiales e imaginarios, pero indudablemente políticos en tanto puebla/nación de impronta nítidamente colonial (21).

Coincidentemente, es desde los confines del feminismo comunitario que emerge el concepto de "cuerpo-territorio", imaginario de inciertos cruces entre cuerpos biofísicos y cuerpos simbólicos, entre primera y segunda piel, coherencia áspera de lo táctil y lo espacial. Aquí se cuestiona la asociación entre mujeres, naturaleza y tierra, para reapropiarla y deconstruirla. Julieta Paredes había expresado el vínculo colonial de la violación en las corporalidades feminizadas y racializadas: "La penetración colonial evoca a la penetración sexual, la violación sexual. Ningún pueblo quiere penetración colonial, ninguna mujer quiere violación sexual" (96). La penetración colonial procesa en este contexto, simultáneamente, la idea de violencia contra los territorios ancestrales y la de violación sexual agudamente condensadas en los cuerpos de mujeres indígenas, ambos constitutivos del imaginario nacional homogéneo y homofóbico:

La penetración colonial nos plantea la penetración como la acción de introducir un elemento en otro y lo colonial, como la invasión y posterior dominación de un territorio ajeno empezando por el territorio del cuerpo. Como las palabras y los discursos, son formas auditivas que toman posición ante las hegemonías discursivas del poder. Podemos decir que la penetración colonial nos puede evocar la penetración coital, como la imagen de violencia sexual, de la invasión colonial (Paredes 96).

5 Feminismos latinoamericanos descoloniales. 
Al aludir al sistemático despojo, la violación opera como desplazamiento de los cuerpos desde la piel a la psique, y de esta a la tierra: "vírgenes violadas las vírgenes que lloran sangre", dice hacia el final del poemario (135). Violación y colonialidad quedan estrechamente vinculadas por cortes, heridas aludidas y elididas. Los cuerpos feminizados y los mapas coloniales se cruzan en el acento deconstructivo de la asociación hegemónica de mujer y tierra, condensación de una "herida libertaria" (21) capaz de reapropiar la cosificación de la otredad, la tierra expoliada y las subjetividades denegadas: mujeres y mestizas. Aquí nada es "natural", porque la propia naturalización es efecto de colonialidad. Así, el poema logra nuevas conjunciones del par cuerpo-tierra, incluidas la desfamiliarización de lo femenino y lo masculino como binarismos excluyentes, posibles en el marco político de una "despatrialización" que es también despatriarcalización lesbopoética, queer, indígena y regional. Lo que Patriagonia desmonta es al menos doble: la agonía de los confines y de las confinadas, poético reparto actorial.

Por eso el texto triádico empieza en desencanto identitario: "recordé entonces que ya no / que la muerte se lo había llevado que mi Patagonia / que mi tierra que mi niñez" (9) Y ese "ya no" abre la escritura de confines. Imposible ya volver a la Patagonia como si fuese "la cosa más plural del planeta", como si se tratase del "cuerpo inmenso de la Tierra" y sus confines (Mistral en Subercaseaux 33), porque son ahora meros “cadáveres los ríos" (Subercaseaux 68), "piltrafas de humanidad” (Subercaseaux 170).

El comienzo alude a sus "delitos provincianos" (Coñuecar 11), fino hilo de desintegración identitaria que posibilitará una profunda y sistemática crítica moral. Por ello, el texto parte de "cero", en la lluvia, para desembocar en furia incendiaria, despojo de patria y matria. Ese es su recorrido. Entonces, volver es también retorno a lo descentrado: Valdivia, un tango, y cita, en ese contexto, "Vuelvo al sur" de Astor Piazzola (12), un "sur que jamás conquistaría" (12). Y volver no sería sino "como el olvido a la historia / como la democracia a la irrealidad / como la privatización a Chile" (14).

Pero recuperar la niñez perdida se acopla a "delitos provincianos". Y a partir de ellos, se establece la mayor ambigüedad textual. ¿Delitos eróticos de una adolescente? ¿Alusiones incestuosas? ¿Violación o cuasifemicidio? ¿De qué delitos se habla? ¿Ma/parricidio? Creo que los procesos de deconstrucción patria y matria de Patriagonia encierran la ambigüedad de las prohibiciones mandatadas al interior de la principal agencia patriarcal, la familia nuclear, pacto colonizador por excelencia; dimensión clave del borramiento de las relaciones de parentesco.

El peregrinaje ritual de los tres libros de Patriagonia me permite recorrer los parajes textuales de una geografía poética cruzada por estallidos subjetivos y geopolíticos, descentrados, agónicos, inscritos en el "ya no" de la distopía micro y macropolítica. Ese espacio textual desafía los estudios culturales. No se trata aquí de tribus rurales. Tampoco de tribus urbanas. Más bien, se trata de una apuesta por despeñadero tribal, por colectivos destribados, inconexos, desgajados de cuajo, excepto en los parcos, intensos roces eróticos. Aquí, la elaboración identitaria hurga en la vaciada comprensión 
del extractivismo patrio: extracción geopolítica de tierras, sí, de tiempos, sí, pero sobre todo despojos subjetivos, sexuales, identitarios. La identidad refractada no implica reconocimiento sin desfamiliarización, proceso asintótico de autodesconocimientos que posibiliten hablar desde sí, desde cuerpos y territorios fragmentados. No hay imaginario consolatorio posible. El recorrido de los tres textos de Patriagonia es agonía lúcida que rechaza familiaridad en un profundo sentido antiedípico y distópico. Soplar para que le devuelvan el "caos", el vacío padre (24), el retorno de lo reprimido, los delitos bajo cero de una "cordillera carcelaria" (26). ¿Cómo no hablar de geoestética política entonces?

\section{Fractal materia, ese cuerpo-territorio}

"Trapananda

sílbame otra vez las grietas de mis tierras” (22).

El uso de la prosopopeya en Ivonne Coñuecar no es meramente reiterativo, sino que se asocia a una geopoética de conexiones inusitadas que cruzan cuerpos, imaginarios y territorios, en formas muy alejadas de usos poéticos tradicionales. La fractal materialidad física en persistente flujo se advierte desde el comienzo en esta trilogía que parte por feminizar el viento catabático (en griego remitía a $\kappa \alpha \tau \dot{\alpha}$, abajo, y a $\beta \alpha i ́ v \omega$, ir). Al ir hacia abajo, el flujo descentra el texto y posibilita el retorno de la memoria a partir de una herida y un "delito provinciano". Ambos refieren a la voluntad deseante de desestabilizar la atmósfera percibida como sexo/familia/región asfixiantes. A su vez, adiabática (también feminizado por la poeta) da cuenta de un fluido proceso termodinámico que impide intercambiar su calor con el entorno, una metáfora deseante expuesta a la sujeción cultural y geopolítica de los cuerpos-territorios. Por último, anabática (también feminizado, del griego anabatos, "moviéndose hacia arriba"), emerge como viento que sopla en forma ascendente sobre pendientes montañosas previamente caracterizadas como carcelarias.

Entendemos que el referente "Patagonia" ha mutado desde 1880, asociado a páramo, lejanía, ocaso, éxodo, soledad, precariedad y riesgo. Sin duda, esa evocación había, a su vez, cambiado desde la noción de "fronteras utópicas" que circunvalaban la Trapananda, hoy Patagonia (Bengoa 19), antiguas tierras de los Kawéskar y Selknam. La rapiña prometida de la distopía marca la diferencia: "todos en busca de la Trapananda al acecho lucrativo / carnívoro / afilado de nuevas políticas de gobierno / el rescate energético de un país que no sabe / que no quiere grados bajo cero" (39).

¿Cómo suenan las batallas interpretativas de pares como "geografía/vientres" (55), "cabello oleaje" (12), "caderas montañosas" (12), "rasguño cósmico" (33), “oscilaciones químicas" (12), o "austral despojo cordillerano" (37)? A partir del ya no distópico del comienzo, Patriagonia desplaza y multiplica los cuerpos-territorios en síntesis dislocadas. El verso traza "rumbos en geografía de nuestros vientres" (55) para dar cuenta de 
parajes internos no recorridos desde el yo, sino desde péndulos de ensimismamiento fragmentario y en flujo: "Corrí la Patagónica. Yo/" y "he vuelto/hambriento naranjo", mientras "a contraluz las nubes desmontan sur" (10). "Agónica geografía” (113), dice, y da cuenta de esa búsqueda "de pies" en totalidad invisible (28), porque cuerpo y patria aparecen siempre invisibilizados desde los trozos desmembrados del cuerpo para sí, "fractura continental", "cicatriz" violentada (20) e irreconocible para el nosotres.

Entonces, los versos se despeñan en búsqueda de un fallido Yo/Patagonia que no es sino agonía de Yo (40), de cuerpo animal a cuerpo geofísico, múltiples seres, múltiples formas de ser y habitar. El relato poético apunta primero hacia abajo y hacia dentro, en descenso identitario que es regreso a los signos del exilio para renombrarse más allá de las lenguas y las bocas. El sujeto cosificado queda así invisibilizado, sin reconocimiento posible. No es solo exilio forzado desde una familia y desde una patria homofóbica. El retorno intro y retrospectivo es propiciado por el duelo y la búsqueda simbólica del padre Huilliche.

Físicos en cuerpo y territorio, los poemas relatan enfriamientos, nieves y flujos, calentamientos, condensaciones, presiones de gases y líquidos, procesos de territorialización y desterritorialización, toda una física poética para poner en juego los pliegues de al menos cuatro relaciones en juego por todo el poemario:

1. Fractura continental del cuerpo-tierra: reapropiación agónica de la aporía entre naturaleza y cultura por parte de la hablante lírica, aún vinculada a la identificación Ser/Tierra expresada en la síntesis, Huilli/Che ("gente del Sur").

2. Catabático arrasar, flujo deseante, desmantelamiento del ideologema patrio. Fin de la ideología como metáfora del "arriba", de lo incorpóreo e inmaterial. El ideologema encarna en roces, en lenguas, en cordilleras, pechos y heridas. El poemario se abre a un escape sin delito para recuperar los cuerpos. Ello implica arrasar el retorno doloso de las marcas esencialistas y excluyentes de la patria. Logra nueva articulación queer de las aporías identitarias de sexo y género, paria y patria; nomenclatura nomádica del peregrinaje sin rumbo ni destino: No soy, estoy siendo, estoy rozando, estoy doliendo.

3. Dimensión geopolítica de los procesos socioespaciales de la nación-estado, campo en disputa por parte de las subjetividades marginadas que rechazan la integración des-subjetivadora y cosificadora de la disidente al "seno" de la madre patria. Percibo esta dimensión cruzada por imaginarios plurinacionales, demanda histórica de los pueblos originarios. La hablante se fuga de la madre y elimina el segundo apellido: "nunca me hiciste cariño" (84).

4) Búsqueda problemática de formas de asociatividad no exploradas, porque "toda identidad es relacional" (Laclau y Mouffe 120) y aquí ese campo es denegado como aniquilador de Yo. 


\title{
El cuerpo. Otra lengua: Patagonia mis pechos
}

\author{
"yo te buscaba Patagonia agonía \\ rasante mis pechos" (40).
}

La combinación "Patagonia" y "mis pechos", nos lleva de afuera hacia dentro, en la mediación del dejar caer identidades estables, ajenas y enajenables. Nunca la nación-estado ha sido más cuestionada desde dentro que en esta guerra intestina lanzada desde el centro capital hacia el Wallmapu, aquí donde el término Mapuche es identificado con el derecho penal del "enemigo interno". Ivonne Coñuecar refiere a una "dictadura sólo para mí" (82), pero a través del poemario va configurando una dictadura al menos doble, de colonialidad chilena y de homofobia familiocéntrica. Si bien esta textualidad patriagónica no se inscribe en el Wallmapu, porque se halla más cercana a las nomadías Kawéskar, lo que permea Patriagonia es la crisis subjetiva y geopolítica de la nación estado posdictatorial:

Chile cae flácido del mapa [...] creyeron que tenía una dictadura sólo para mí / estamos listas para morir. así es la historia. construyo un búnker y ella arma con cariños los ladrillos de mi muro / me da piedritas como besos. tengo fierros adiabáticos que me cruzan sin dolor. y sonrío / saludo / pregunto si está bien de profundidad. soy la chica dócil de la primera y segunda noche (81-82).

Homofóbica, la patria se desmorona, se cae en el desbarajuste de la dictadura aunque las jóvenes lésbicas se aman, irónicas, con "piedritas como besos" - "chica dócil de la primera y segunda noche"- una vez que los delitos provincianos se hayan desmurallado. Aquí, la dictadura y la transición concertacionista no despegan; son más bien reinvenciones que no dan con el deseo ciudadano de un estado plurinacional. ${ }^{6}$ Nunca ha sido más cuestionado este "Chile profundo" que en la proliferación de centros de colonialidad interna a partir de los efectos de la agropolítica de nueva industria agropecuaria. La hablante se halla en un territorio híbrido con múltiples centros extractivos regionales que no son ni rurales ni urbanos, todos directamente anexados a las transnacionales del hipermercado globalizado. Sabemos, claro, que esos espacios anexados se descentran como ejes rururbanos, no solo capaces de extraer minerales, manzanas, forestales o salmones, sino sobre todo subjetividades, a partir de sujeciones singulares y colectivas.

6 Ver Convenio 169 de la Organización Internacional del Trabajo sobre Pueblos Indígenas y Tribales en Países Independientes de 1989 (www.ilo.indigenous/conventions/lang--es) y la Declaración de las Naciones Unidas sobre los Derechos de los Pueblos Indígenas de 2007, aprobada durante el $61^{\circ}$ periodo de sesiones (https:// www.ilo.org/wcmsp5/groups/public/---americas/---ro-lima/documents/publication/wcms_345065.pdf). Ver también el Convenio 107 de la OIT; el mandato del Estado-Nación presuponía que los pueblos indígenas y tribales eran "sociedades temporarias destinadas a desaparecer con la modernización" (www.ilo.org/indigenous/conventions/ $\mathrm{n}^{\circ} 107$ ), aun cuando su existencia sea anterior a la construcción del Estado-Nación o del trazo de las fronteras. En ese contexto, el modelo de Estado-Nación desestimó la pluralidad nacional que conformaba su población, habiendo en cambio aplicado abiertas políticas de genocidio o lentos procesos de asimilación, simbólicas silentes de genocidio. 
Situada explícitamente en los bordes de la nación, Patriagonia revela que no son "las naciones las que hacen a los estados y forjan el nacionalismo, sino todo lo contrario" (Hobsbawn 78). Aquí el concepto de "nación”, se ha alejado cada vez más de la idea de "pueblos" y "culturas" (Kymlicka 26). Por eso, la problematización de la nación unitaria desesencializa varios términos de coherencia semiótica. ¿Es la nación un credo de cohesión? ¿Un deseo de pertenencia y arraigo? ¿Lazos filiales simbólicos sin territorialidad ni cuerpo? ¿Una lengua físicamente resguardada por aparatos represivos? ¿Qué es esta forma ilustrada de nacionalismo neocolonial y trasnacional? El nacionalismo esencialista va revelando con insistencia su matriz:

El nacionalismo es eso: un fraude. Inventa un pueblo homogéneo con una historia común y un futuro compartido: instaura una fraternidad excluyente: nos envuelve en una cinta hermética que nos protege de una exterioridad abominable[...] El nacionalismo fantasea sobre la irrepetibilidad de nuestro destino (Silva-Herzog 16A).

En Chile, la Revuelta de O19 se tomó al país por su eje, el cetro de Baquedano pintado y repintado de consignas por la dignidad. Aún resuena el "Chile despertó" en nuestros oídos y la bandera luce trastocada de negro con sus miles de duelos a cuestas mientras la hablante poética afirma que "zurce una bandera a su piel” (Coñuecar 72). ¿Es la cuestión nacional, como el sexo y la raza, una incertidumbre identitaria? ¿Es la nación, como la "sagrada familia" heteronormativa, un ideologema situado, espacializado, historizado en condiciones de enunciación particulares? ¿Un cierto tribalismo en persistente amenaza de disgregación? ¿Un cúmulo de fechas emblemáticas? ¿Un símbolo homogéneo que coagula la heterogeneidad? ¿Una falla en el propio sentido de lo "común"? ¿Cómo se articulan los sujetos singulares y colectivos con la naciónestado en la que se instituyen? ¿Cómo se genera la hebra que las y los teje? ¿Cuál es la fibra integradora? ¿Una cierta épica, un sistema de coerción?

Patriagonia devela la andrógina madre patria como adherencia vinculada a los estados dictatoriales y coloniales para hacer converger dos procesos: uno constitutivo de nación-fraude y un sistema de dominación heterogéneo, arco inestable de alianzas que opera como velo de diferencias, inequidades y sometimientos. Territorio y sexo quedan así urdidos desde el comienzo. 


\section{Eluwün: No más padre}

“justo aquí nos repite con voz huilliche tú y yo sabremos resucitar justo aquí (45).

Entendemos que el cuerpo desmembrado aparece como un "ya no" identitario desgajado del Yo/territorio que queda suspendido para la mestiza en un todavía nostalgioso, hilo del que pende el inestable y agónico término Huichille de duelo (Eluwün), descenso mestizo al fondo de sí. Duele por eso el retorno denegado que al comienzo del poemario involucra a la niña suicida de 17 años, aquella que rompía "vidrios para cortarse las venas" (8), y que había internalizado el tabú heteronormativo asociado a los provincianos "delitos" de lesbianismo y repulsa materna. La memoria parte desde un "ya no" porque la Patagonia, la suya, la tierra de la niñez, se encuentra fisurada, elidida, bloqueada. Los tiempos se recorren en vaivén, en un "volver pensando que era antes" (8) y por esa fisura resuena el "latido abisal" del éxodo patrio (8). Emergen laderas del destierro, los amores de Valdivia, la memoria abismal de sus "delitos provincianos" (11) y entonces la "tierra cede resquebrajándose" (20) en movimiento, un "trance telúrico" en las "fronteras de la piel" (26). El ciclo de éxodo y retorno parece cumplirse, aun cuando sea en el dolor: "abandoné mi tierra patagona [...] para ser alguien / para cumplir mis sueños de ellos” (32). Pero la enajenación lo cruza todo. Los sueños y las prohibiciones le son ajenas. Por eso, el regreso queda marcado por un tajo que alude a reiterados intentos de suicidio, al quiebre con el Yo patrio, con el Yo hija/hijo de la familia nuclear híbrida (padre Huichille y madre chilena). Entonces, el verso se lanza sobre una paternidad otra, desde siempre dolor enterrado. En este campo devastado va emergiendo una episteme que recupera el caos en la poesía, porque no se trata, pues, de geografía, sino de ir al encuentro libertario con el caos, con esa inestable inutilidad que es el arte (30). Por ello, finalmente, insiste, no era loca la geografía, sino las formas de nombrarla:

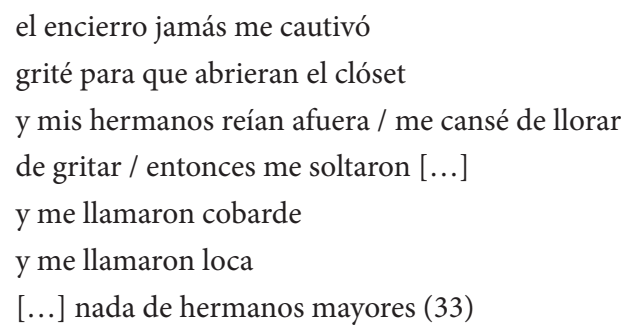

La niñez remite aquí a fisura, a "espera sin sentido" para volver a la diferenciación de los procesos incompletos de subjetivación en tierra perdida, en tiempo perdido, ante el cuerpo presente del padre muerto y la censura de su "carne roja" y disidente. Un ritmo, un brío impaciente. Una colonialidad en Valdivia, "ciudad europea. Películas sin sueños" (10). Frases llenas de carne, parábolas y deseos denegados: "Aprendí a 
boicotearme / a asaltarme en la esquina" y "no quise hablar de la carne roja" (18), blanqueada por el olvido, por la impunidad individual y colectiva. El regreso nada resuelve: "herida libertaria, saquito roto, cesantía, náusea peregrina" (21).

\title{
Catabático arrasar del desamor. Lengua aguja
}

\author{
"mi herida patagónica / mi dictadura \\ estos / mis padres y madres" (65). \\ "la evidencia del abandono" (50). \\ "abrázame que me lluevo y no sé llorar" (51).
}

Catabática parte por un verso: "dijeron que me lo merecía pero que ya no" (mi énfasis). A partir de allí, el texto se desgrana en búsqueda de otro tiempo, frente a palabras y mandatos ajenos, en lengua rítmica, esdrújula, en son oral. Allí inicia la labor de nombrarse sujeto a través de signos de carencias, cúmulos de rechazos y abandonos, en primera persona o en palabras de otras: "A la otra sî" (42).

En la propia lengua, en la herida, se produce el parto de la diferencia, porque de esos mismos flagelos crecen bocas, lenguas partidas, toda una sintaxis otra (39). Persistente, el desamor desplaza el sintagma "amo" por la carne roja, para volcarse al entramado desfamiliarizador: "Yo tuve querida / un hombre y una mujer que me amaron / y no se llamaban padres / no se llamaban hermanos" (39). Al asumir la orfandad y el desamor, la hablante arrasa con el ideologema de la familia nuclear; reniega de la madre muerta camino del cementerio y rememora la hiriente diferencia: "cómo se grita / cómo se punza el pecho / cómo no hay consuelo / coincidimos todos como hermanos de distinta madre" (49).

\section{Eluwün}

Me detengo en la estación sin rumbo de Eluwün, ritual de plurales duelos. Es un poemario dentro de otro poemario, puesta en abismo, cajita de pandora. Allí la pérdida y los restos de la madre aparecen como errores, equivocación de "ciudad madre" (49), justo cuando se persigue la muerte y se pierde la virginidad (42). Duelo de madre y padre, Eluwün marca la pérdida de fe religiosa, la injusticia, el fin de la "crédula inocencia": "lo que pudo parecer amor [...] mentira serpenteante / te como justo aquí el almita / justo aquí tus piernas" (42). Antiedípica y fugaz, el amor debe morir para dar lugar a una paseante orfandad carnal y deseante. Fin del aura romántica. Porque aquí su peregrinaje destraba el ideologema de la madre patria (madre chilena) al mismo tiempo que se distancia del simbólico parricidio patrio de los confines (padre Huilliche). Muerte y resurrección se articulan entonces como productividad deseante: "Te 
canto con ritmo de Eluwün", dice, en punto de resurrección: "quedo ahora en silencio y creo mi propia historia”, descreyente y carente del "arte del perdón” (48). Eluwün se convertirá en punto de agonía y bitácora de viaje, andrógina, "huérfana" y "colono", conexión agónica de lo femenino y lo masculino hegemónico (46-47).

Solo desde y por el duelo paterno, así como del rechazo de la madre colonial será posible acceder al "yo", a la "palabra más allá de la muerte" (47), la palabra herida (52). Erótica, curvado su cuerpo, la hablante abre los sentidos "en el olor de maduras frutillas rojas sin sangre” (53). El propio duelo se abre a subversiones deseantes y corpóreas más allá de los estrechos marcos moralistas: "hasta tus caderas nado, invítame a navegar [...] al viento mis pechos escriben" (54); "Arrullemos la fuga [...] sin cuerpo del delito" (55). Entendemos que la muerte del padre abre la denuncia, el reconocimiento más allá de las prohibiciones, el roce sin delito, sin moralina. El territorio que encuentra es la poesía: "adentro de la música para tener una patria" (54). Así serán los signos que rememoran y reactualizan la orfandad, en su materialidad doble de nombrar y trepanar, de corte y construcción. Eluwün abre la dimensión geopolítica de los procesos socioespaciales, desmantela la nación-estado, desde las subjetividades marginadas por el "acecho lucrativo / carnívoro / afilado" y por las siempre renovadas políticas posdictatoriales: "rescate energético / de un país que no sabe / que no quiere grados bajo cero" (39).

\section{Todos en busca de la Trapananda}

“y yo, marginal” (48). “zurzo una bandera a mi piel” (72).

“Todos buscan la Trapananda” remite a la rapiña material y simbólica del extractivismo: isla del tesoro, desmesura, paraíso recóndito, lugar de invención, paraíso perdido, utopía de riqueza y aventura, tierra de nadie, espacio fronterizo, marginal, territorio privilegiado de los "primeros", los colonos y su infierno de promesas. Ese fuego de tierra anunciará el apocalipsis, la quemazón final con que concluye el poemario:

\footnotetext{
dice que se quema, que asciende, que sube por el aire es el viento incendio le digo

la Patriagonia arde desde que el hombre puso su pie y sus manos progreso abrieron camino despejaron la tierra con infierno de promesas (129).
}

Más tarde, nos recordará el poemario, la Patagonia será asociada con una "reserva de vida" (Núñez et al.), reserva que el texto de Ivonne Coñuecar deconstruye paso a paso, a nivel metonímico, pasando por la irónica visión de la inauguración de la "Carretera Austral general augusto pinochet" (78). Hacia el final, la voracidad de las llamas vuelve literalmente la tierra ígnea en Tierra del Fuego. En este sentido, 
Patriagonia da cuenta del "giro cultural" en la geografía y de las múltiples ficciones de dominio enquistadas en "lo natural". Trapananda ha adquirido indudablemente la mixtificación, la fascinación y el desprecio asociado al orientalismo (Said 24). Dice Coñuecar

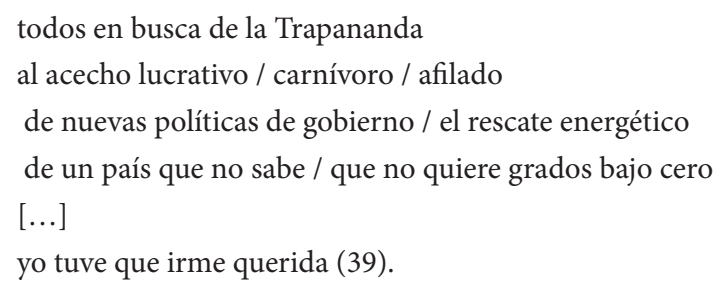

Una bitácora de viaje por los cruces personales y comunitarios del sistema de coerción, la poética de Patriagonia asume lo fronterizo en flujo, en ética memoriosa: "a mí no se me olvida nada de las calles. paseo con la memoria como manojo de tripas revueltas" (75). ¿Un ideologema situado, espacializado, historizado en condiciones de enunciación particulares? Confusos, los sentidos nacionalistas se van coagulando en un cúmulo de aparatos ideológicos del Estado: familia, escuela, iglesia, invención de ceremonias públicas, producción masiva de monumentos y emblemas patrios.

Rescato aquí la poetización crítica de la nación-estado a partir de la articulación entre geografía e imaginario social, entre sujetos de la nación y sujeciones del Estado. No habría noción de estado-nación sin sujetos y actores sociales. ¿Cómo se articulan esos sujetos singulares y colectivos con la nación-estado en la que se instituyen? ¿Qué tensiones las constituyen? ¿Cómo se genera la hebra que las y los teje? ¿Cuál es la fibra integradora y cuánto es resistida? Esa adherencia nacional emerge aquí vinculada a las dictaduras y al desarrollo neoliberal de la expansión capitalista. Patriagonia nos sitúa ante una convergencia de procesos constitutivos de nación y sistemas de dominación heterogéneos, arco de afinidades asimiladoras de diferencias, pero no garante contra inequidades ni sometimientos.

Cuando llegamos a Adiabática, la bitácora de viaje se inscribe sobre la "piel travesti" desafiante del miedo neonazi, de los procesos represivos del estado, del "miedo dictadura" en el siglo veintiuno $(69,71)$ :

prendida la televisión en el machismo de este país [...] no a este desarrollo de país sin cariño [...] quiero mirarte en la calle con mi miedo a gritos / mi miedo retrato camina con mis masculinidades y feminidades / edades sin libido ni placebos. no entiendes cómo desperdicié noches besando esponjas que latían / ni cómo duele no ser crisálida / unicelular. no es como cambiar de ropa o país y cruzar la frontera limpia y revisada / sin discurso / ni maquillaje / ni política / sin piel / ni otredad. nunca cruzamos la frontera / nunca salimos de nuestro país abecedario (70). 


\title{
Lo personal es político. Lengua voraz y veraz
}

\author{
"hicimos de las torturas un rito de baile" (73). \\ "mi padre dijo maricones y lesbianas traen mala suerte" (85).
}

El lenguaje poético se politiza. Se ha salido de las casillas poéticas, de la densidad figurativa. Ha destapado los pliegues de la autocensura y el silencio, cargando dolores y verdades no dichas. Ya no hay secretos. Los armarios se hallan abiertos: "se me arrancan del clóset las palabras". Es 1973 y Patriagonia se llena de "gritos de torturados" en el Estadio Nacional. La hablante aclara que "ella no sabe los golpes de un país anestesiado" allí donde "los ratones carcomían los úteros" (73), allí donde se produce el derrumbe hacia el "libre mercado" y "pagamos a crédito nuestro rito de sufrimiento" (73). Mordaz, la ironía avanza contra la banalidad de la posverdad:

llegaron los yanquis a esta luna chilena / el mtv / comida rápida los nuevos grupos musicales entraban por mi personal stereo / el grunge acarició mi orfandad spanglish. ¿quién se atreverá a decir la verdad ahora que no hay dictadura? / ¿quién se desnudará ahora que no somos mayoría? (75).

Resuenan en la piel, la apertura de la Antártica, la "soda cáustica en los cerros":

Carretera Austral llamaron a todo eso / para mí no tuvo nombre hasta que me fui / entonces eché de menos no saber nombrarla / y se llamaba Carretera Austral general augusto pinochet i mi región se llamaba del general carlos ibáñez del campo. pero yo no les debo nada a los milicos (78).

Sabemos que la Trapananda se transformaría en turismo aventura para el siglo XxI. Que quedaría recubierta con un brillo mercantil de energía y pureza, "natural" reserva de vida, modernización de consumo y turismo ecológico. Entonces la diferenciación se fundirá en desigualdad, en democracia vaciada de sentido, en ligazones sociales jerárquicas, autoritarias, patronales, patriarcales, homofóbicas, entre panópticos, ciudadanías tuteladas y visiones refractadas: "cuántas calles y secretos padre / ni imaginas cómo besaban esas mujeres quinceaños" (92), pero "nos regalaron femicidios" (96).

La agonía de la patria se ha convertido en lucidez. En el seno de las operaciones, se advierten nudos críticos de una nación "que no es una", que pugna por abrirse a los desvaríos poéticos del hablar las diferencias, en la agonía de una indiferencia que no es sino solapada forma de disciplinamiento y control. 


\section{Declaración: "Desnuda me hago mujer. No temo a las calles Coyhaiqueer"}

Hacia el final, Anabática sale del armario; la escritura se desenfada, burlona, sin tapar heridas ni orfandades deseantes. Está aburrida, dice, de "buscar soluciones y oídos para monólogos" (121). Porque, agrega: "no ves que crecen alas y ya nada dolerá" (121).

Ha encontrado una salida por la prosa burlona, las confesiones a los cuatro vientos, el manifiesto, las declaraciones:

lindo el niñito mujer dentro del clóset [...] no temo a las calles de Coyhaiqueer (113).

no es un juego ser pobre ni ser rico en Coyhaiqueer. los espacios se dividen: zona de guerra y tierra de nadie. y viceversa [...]. los chicos pobres y los chicos ricos me enseñaron a quedarme callada (112).

Declaro que

me rapé la cabeza

[...] Declaro que

Consumo drogas Sufro de insomnio Mal humor No cuido la línea Declaro que vigilan los libros que leo Dicen no se junten con ella (111).

hice confesiones drag king

soy el chico amanerado. ellas no creen

que pueda jugar con muñecas

quiero ser una mujer fatal cuando hablo de mi ego

y hago gestos de mi caos

camino en el fascismo de mi Coyhaiqueer

$[\ldots]$

escapándome los accesorios drag king

ella conoce mi caos cuando desnuda me hago mujer (120).

La hablante reniega del pasado, pero no del recorrido. Se ha cansado de la sangre y las heridas, de los coágulos y las venganzas. Entonces quema los malos recuerdos y las fotografías familiares porque había "sangre en mis fotos de pequeña" y "cabezas cortadas" (118). Los padres y las monjas se han ido y vuelve hacia atrás, a los quince años, a bajarse los cierres, a "respirar apresuradas de fuego y ansia", a rasgar las "ropas incendiadas y amanecer de nieve" (115), abierta a los roces con los árboles, de piel a piel. 


\section{Incendios de fin de mundo: Anabática libertaria}

Nadie quiso aceptar el apocalipsis hasta que soltaron el hocico globalización” (127).

Hacia la conclusión, Patriagonia se vuelca, contradictoria y libertaria, a los vientos ascendentes del fuego; incendios incontrolables "ardieron por décadas y décadas", convirtiendo a toda la ciudad en "cráter volcánico", con suicidios hambrientos y bienvenidas a las "tropas que llenaron de armas nuestra tierra" convertida en "ciudad derecha" (127). Pero aquí el fuego es también onanismo, retiro y combate: ha aprendido las artes amatorias de la masturbación, la guerra y la escritura. Pero la moralina no ceja: "no dejan salir a la niña bomba personal que grita revolución para sus adentros mientras sigue amarrada dentro de un clóset" (146). Insiste: "He hablado del incendio que vive en mi médula" (138). Pero solo una adolescente sobrevive al fragor de su memoria, durmiendo bajo la nieve, mostrando cicatrices y quemaduras. Es el sexo-territorio lo que quema y recuerda: "nos quemamos de nuevo porque mi padre dijo si te quemas dos veces ya no duele y no dolió" (140). Invertida, asciende hasta su apocalipsis, besando, quemándose en el "infierno bajo la nieve" (129):

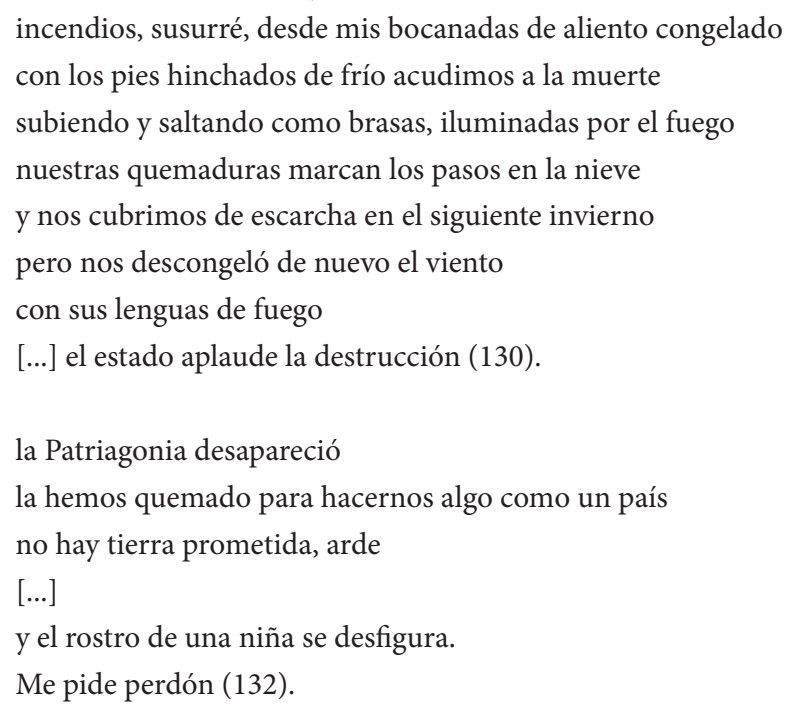

\section{A modo de cierre. Chile: Un "encierro de libertad"}

Ivonne Coñuecar nos ha expuesto a tránsitos, poéticas, prosas y declaraciones. Intro y retrospectivas, estas son capaces de dar cuenta de profundas transformaciones identitarias, ensimismamientos vaciados en periferias, deshielos, virajes y fuegos. Hemos advertido una peregrinación identitaria desde un antes y un después. No se trata de travesía patria ni matria, sino de bisagras que desatan movimientos desco- 
lonizadores y desfamiliarizadores. Allí, y este no es un camino, se han descentrado estos saltos poéticos, intentando trazar escasos buceos de sentidos, aquí donde cruje el verbo para condensarse en esdrújulos in/significantes, feminizados o andróginos: catabática, adiabática, anabática. Se trazan subjetividades singulares y colectivas que se desplazan, ajenas, siniestras, desconectadas o desintegradas en las tierras de "entremedio". ¿Colonos o colonializados? ¿Cuáles son los límites de este territorio mercado-céntrico de múltiples naciones? ¿Transfigurar la periferia o dejar el espacio verde de la biodiversidad, precisamente como paradigma periférico exportable? ¿Cómo no reconocernos en este relato de los confines de la nación?

Paraíso reclamado o perfecta indiferencia ante el oro, la plata y las riquezas, aquí Patagonia queda asociada a la distopía, al reino de "espacios intermedios" y mestizajes no biológicos, una aculturación como juegos de espejos en los que persisten la mutua desconfianza, la fricción, la expropiación de territorialidad y de subjetividades Huilliche. El aplastante triunfo en las recientes elecciones para una nueva Constitución nos abrirá al debate y a la posibilidad de pronunciarnos frente a la un estado plurinacional y paritario. Identidades rururbanas, sentidos múltiples de expresiones poéticas, Patriagonia nos ha develado la particular reterritorialización de los modos en que se esparcen los imaginarios políticos, personales y colectivos, ante el desconcierto de la globalización neoliberal.

\section{Referencias}

Aliste, Enrique y Andrés Nuñez. "Las fronteras del discurso geográfico: el tiempo y el espacio en la investigación social". Chungara, Revista de Antropología Chilena, vol. 47, n.o 2, 2015, pp. 287-301. Doi: http://dx.doi.org/10.4067/S071773562015005000023

Bengoa, José. La emergencia indígena en América Latina. Santiago, Fondo de Cultura Económica, 2012.

Castoriadis, Cornelius. La institución imaginaria de la sociedad. (1. ${ }^{\mathrm{a}}$ ed.). Barcelona, Fábula Tusquets Editores, 2013.

Cepal. Población, territorio y desarrollo sostenible. Naciones Unidas, Chile, 2012. LC/L.3475(CEP.2/4)

Coñuecar Araya, Ivonne. Patriagonia. Santiago, LOM, 2014. Recuperado de: https:// lom.cl/a/a129388f-126b458d-988a-e432f0cc7dcc/Ivonne-Co\%C3\%B1uecarAraya.aspx

De Certeau, Michel. La invención de lo cotidiano 1. Artes de hacer. México, Universidad Iberoamericana, Instituto Tecnológico y de Estudios Superiores de Occidente, 1996.

Foucault, Michel. Vigilar y castigar. Nacimiento de la prisión. México, Siglo xxi, 1976. 
Gorelik, Adrián. "Imaginarios urbanos e imaginación urbana. Para un recorrido por los lugares comunes de los estudios culturales urbanos". EURE (Santiago), vol. 28, n. ${ }^{\circ} 83$, 2002. Doi: http://dx.doi.org/10.4067/S0250-71612002008300008

Hammerschimdt, Claudia. Patagonia literaria: fundaciones, invenciones y emancipaciones de un espacio geopolítico y discursivo. (1. a ed). Londres: Inolas Publishers Ltda, 2016.

Hobsbawm, Eric. Naciones y nacionalismo desde 1780. Barcelona, Crítica, 1998.

Kymlicka, Will. Ciudadanía multicultural. Barcelona, Paidós, 1997.

Laclau, Ernesto y Chantal Mouffe. Hegemonía y estrategia socialista. Hacia una radicalización de la democracia. (1. ${ }^{a}$ ed). España, Siglo xxi, 1987.

Lefebvre, Henri. "Plan de la Obra”. En La producción del espacio. (1. ed.). Madrid, Capitán Swing, 1974.

Mansilla, Sergio. “Adiabática yo”: memoria, nomadías y localizaciones en la poesía de Aysén (en torno a la escritura de Ivonne Coñuecar)". Eds. Tatiana Calderón y Edith Mora, Afpunmapu/Fronteras/Borderlands. Poética de los confines: Chile-México. (1. ${ }^{\mathrm{a}}$ ed.). Valparaíso, Ediciones Universitarias de Valparaíso, 2015, pp. 147-169).

Mistral, Gabriela. "Prólogo". Chile, o, una loca geografía. Benjamín Subercaseaux, 11. ${ }^{a}$ ed. Santiago, Universitaria, 2001.

Moraga, Fernanda. "Catabática: cartografías de subjetividades fronterizas”. Literatura y lingüística, n. ${ }^{\circ}$ 26, Santiago, 2012, pp. 47-59. Doi: http://dx.doi.org/10.4067/ S0716-58112012000200004

Núñez, Andrés, Enrique Aliste y Federico Arenas. "Paisajes en fuga. Imaginarios y arquitecturas geográficas de la Patagonia”. Revista AUS, n. ${ }^{\circ} 22,2017$, pp. 40-45. Doi: 10.4206/aus.2017.n22-07

Ochoa, Karina. "Una apuesta posible: mujeres, lucha por la autonomía y perspectiva descolonial en el Abya Yala”. Coord. Verónica López Nájera, De lo poscolonial a la descolonización. Genealogías latinoamericanas. México, UNAM, 2018.

Ochoa, Karina et al., coeditora. Tejiendo de otro modo: Feminismo, epistemología y apuestas descoloniales en Abya Yala. Colombia, Lemoine, 2013.

Paredes, Julieta. "Hilando fino desde el feminismo indígena comunitario". Coord. Yuderkys Espinosa, Aproximaciones críticas a las prácticas teóricas políticas del feminismo latinoamericano, Tomo I, 2010, pp. 117-120).

- - . "Las trampas del patriarcado". Coord. Diana Urioste, Pensando los feminismos en Bolivia, Serie Foros 2. La Paz, Conexión Fondo de Emancipación, 2012, pp. 89-112.

Said, Edward. El orientalismo. Barcelona, Debolsillo, 2002.

Silva-Herzog Márquez, Jesús. "Cuesta y el nacionalismo". Reforma, 15 (septiembre 2003), p. 16A.

Subercaseaux, Benjamín. Chile, o, una loca geografía. 11. ed. Santiago, Universitaria, 2001.

Enviado: 3 de noviembre de 2020

Aceptado: 9 de diciembre de 2020 